\title{
Uji Residu Antibiotika dalam Paru-Paru Sapi Bali dari Beberapa Pasar di Provinsi Bali
}

\section{(ANTIBIOTIC RESIDUAL TEST IN LUNGS OF BALI COWS FROM SOME MARKETS IN BALI PROVINCE)}

\author{
Maria Elysabet Pane ${ }^{1 *}$, Siswanto ${ }^{2}$, I Wayan Sudira ${ }^{3}$ \\ ${ }^{1}$ Mahasiswa Program Profesi Dokter Hewan, Fakultas Kedokteran Hewan, Universitas \\ Udayana, Jln. PB. Sudirman Denpasar Bali; \\ ${ }^{2}$ Laboratorium Fisiologi Veteriner Fakultas Keokteran Hewan, Universitas Udayana \\ Jalan. PB Sudirman, Denpasar-Bali; \\ ${ }^{3}$ Laboratorium Farmakologi Veteriner Fakultas Keokteran Hewan, Universitas Udayana \\ Jalan. PB Sudirman, Denpasar-Bali. \\ *Email: alexyath33@gmail.com
}

\begin{abstract}
Abstrak
Penggunaan antibiotika pada peternakan sapi yang tidak tepat misalnya dosis yang berlebihan, dan tidak memperhatikan masa henti obat (withdrawal time) dapat menimbulkan residu antibiotika pada daging dan juga organ dalam ternak. Waktu henti obat adalah kurun waktu dari saat pemberian obat yang terakhir hingga ternak boleh dipotong atau produknya daging dan organ dalam dapat dikonsumsi. Paru paru merupakan salah satu organ dalam yang terdistribusi antibiotika yang bila tidak memperhatikan waktu henti obat sebelum pemotongan maka pada organ paru paru akan masih terdapat zat aktif dari antibiotika tersebut sehingga menyebabkan adanya residu antibiotika. Penelitian ini bertujuan untuk mengetahui adanya residu antibiotika dalam paru paru sapi bali dari beberapa pasar di provinsi Bali. Sampel paru sebanyak 30 diambil dari beberapa pasar di lima kabupaten yaitu Tabanan, Gianyar, Buleleng, Jembrana dan Karangasem kemudian diuji menggunakan metode bioassay di Balai Besar Veteriner Denpasar. Hasil pengujian tersebut menunjukkan dari 30 sampel paru paru tidak mengandung residu antibiotika dari golongan penisilin, aminiglikosida, tetrasiklin dan makrolida.
\end{abstract}

Kata kunci: residu antibiotika; paru-paru; sapi bali; provinsi Bali.

\begin{abstract}
The use of antibiotics in inappropriate cattle ranches, for example, excessive doses, and no regard for drug withdrawal can cause antibiotic residues in the flesh and also the organs in livestock. The withdrawal time is the period from the last drug delivery to the livestock before the animal can be slaughtered so the meat and internal organs can be consumed. The lung is one of the internal organs distributed antibiotics that when not pay attention to the time of stopping the drug at the time of cutting the lung organ will still contain active substances from these antibiotics that cause the presence of antibiotic residues. This study aims to determine the presence of antibiotic residues in the lungs of bali cattle from several markets in Bali province. 30 lung samples were taken from several markets in five districts of Tabanan, Gianyar, Buleleng, Jembrana, and Karangasem and then tested using the bioassay method at Balai Besar Veteriner Denpasar. The results showed that 30 lung samples did not contain antibiotic residues of the penicillin, aminoglycoside, tetracycline, and macrolide groups.
\end{abstract}

Keywords: Residue antibiotics; pulmonary lung; bali cattle; Bali province.

\section{PENDAHULUAN}

Ternak sapi potong di Indonesia, salah satunya adalah sapi merupakan salah satu sumber pangan yang sangat dibutuhkan (Besung et al., 2019. Menurut data Badan
Pusat Statistik (2012) menunjukkan konsumsi daging sapi dan jeroan masyarakat Indonesia sebesar 2,14 $\mathrm{Kg} / \mathrm{kapita} / \mathrm{tahun}$. Adapun pasokan jeroan sapi yang dikonsumsi masyarakat mencapai 
78.000 ton. Konsumsi daging sapi yang terus meningkat dan kebiasaan masyarakat Indonesia yang gemar mengkonsumsi jeroan sapi membuat kebutuhan akan ternak sapi kian meningkat (Kussoy et al., 2019).

Produksi ternak yang terus menerus ini harus diimbangi dengan pemeliharaan kesehatan ternak yang baik. Dalam mempertahankan kesehatan sapi, beberapa peternak memberikan antibiotika baik untuk pengobatan maupun mempertahankan kesehatan. Antibiotika adalah bahan alami atau semi sintetis yang memiliki daya kerja untuk membunuh (bakterisidal) atau menghambat pertumbuhan bakteri (bakteriostatik). Antibiotika yang sering digunakan dalam peternakan antara lain golongan penisilin (prokain penisilin $\mathrm{G}$ dan kalium penisilin G), golongan tetrasiklina (tetrasiklin, oksitetrasiklin dan klortetrasiklin), golongan aminoglikosida (gentamisin sulfat, neomisin dan dihidrostreptomisin sulfat) dan golongan makrolida (eritromisin) (Phillips et al., 2004)

Menurut Nugroho et al. (2002), pemantauan residu antibiotika di tiga provinsi (Sumatera Barat, Riau dan Jambi) dari tahun 1998-2002 yaitu total positif residu antibotika penilisin mencapai $0,18 \%$, tetrasiklin 1,84\%, aminoglikosida 3,95\% dan sulphonamida 3,76\%. Ini menunjukkan tingginya penggunaan antibiotika yang tidak tepat sehingga menyebabkan residu antibiotika

Penggunaan antibiotika yang tidak tepat misalnya, dosis yang berlebihan, dan tidak memperhatikan masa henti obat (withdrawal time) dapat menimbulkan residu antibiotika pada daging dan juga organ dalam ternak (Maron et al., 2013; Chattopadhyay, 2014). Waktu henti obat adalah kurun waktu dari saat pemberian obat yang terakhir hingga ternak boleh dipotong atau produknya daging dan organ dalam dapat dikonsumsi. Waktu henti antibiotika tidak sama tergantung daripada jenis antibiotika, cara pemberiannya dan juga dipengaruhi oleh arbsorbsi, distribusi dan juga ekskresi dari antibiotika tersebut. Menurut Murtidjo (2007), pada umumnya antibiotika bersifat mudah larut dalam lemak dan dapat dengan mudah melewati membran-membran sel atau jaringan sehingga dengan cepat didistribusikan ke seluruh jaringan tubuh, termasuk ke paru paru, hati dan ginjal. Pengeluaran antibiotika terjadi melalui proses biotransformasi dan ekskresi yang berlangsung lama sehingga pada waktu pemotongan jika tidak memperhatikan waktu henti obat yang benar dan tepat maka antibiotika yang telah diberikan masih tersisa dalam bentuk metabolit dan menimbulkan residu pada produk asal hewan, salah satunya adalah organ paruparu.

Kesadaran akan bahaya residu antibiotika dalam produk peternakan masih kurang mendapatkan perhatian, karena pengaruhnya memang tidak terlihat secara langsung akan tetapi akan membahayakan kesehatan manusia, apabila produk peternakan yang mengandung residu dikonsumsi secara terus menerus setiap hari. Dampak negatif dari pemakaian antibiotika adalah reaksi alergi, toksisitas, mempengaruhi flora usus, respon imun, resistensi terhadap mikroorganisme, pengaruh terhadap lingkungan dan ekonomi.

\section{METODE PENELITIAN}

\section{Sampel}

Paru-paru sapi bali sebanyak 30 sampel diperoleh dari masing-masing dua pasar tradisional di lima kabupaten di Bali yaitu Tabanan, Gianyar, Buleleng, Jembrana dan Karangasem. Di setiap pasar diambil masing-masing tiga sampel dengan berat 100 gram.. Penentuan lokasi pengambilan sampel dilakukan secara acak.

\section{Pengujian residu antibiotika}

Sampel paru-paru ditimbang sebanyak 10 gram, kemudian ditambahkan $20 \mathrm{ml}$ dapar fosfat $\mathrm{pH} 7,0$ dan disentrifugasi dengan kecepatan $3000 \mathrm{rpm}$ selama 10 menit, selanjutnya diambil supernatannya. 
Sementara itu kultur media agar disiapkan untuk masing-masing kelompok antibiotika. Selanjutnya kertas cakram steril diletakkan di atas permukaan kultur media. Sampel diambil $75 \mu l$ lalu diteteskan pada kertas cakram. Larutan bakteri uji sesuai dengan jenis antibiotika yang akan diuji di teteskan pada kertas cakram sebagai baku pembanding kontrol positif, dan larutan dapar fosfat sebagai kontrol negatif. Setiap cawan petri berisi 5 kertas cakram, yang terdiri dari 3 kertas cakram dari sampel paru paru yang berbeda, 1 kertas cakram untuk larutan baku pembanding sebagai kontrol positif, dan 1 kertas untuk larutan dapar fosfat sebagai kontrol negatif. Biakan tersebut diinkubasikan ke dalam inkubator dengan suhu yang berbeda untuk setiap antibiotika (grup tetrasiklin suhu inkubator $30{ }^{\circ} \mathrm{C}$, grup makrolida dan aminoglikosida $36^{\circ} \mathrm{C}$, dan grup penisilin 55 $\left.{ }^{\circ} \mathrm{C}\right)$ selama 18 sampai 24 jam.

\section{Analisis data}

Diameter daerah hambatan yang terbentuk di sekeliling kertas cakram diamati dan diukur dengan menggunakan jangka sorong. Sampel dinyatakan positif mengandung residu antibiotik apabila terbentuk zona bening (daerah hambatan) minimal $2 \mathrm{~mm}$ lebih besar dari diameter kertas cakram. Golongan penisilin dinyatakan positif maka harus dilakukan uji ulang dengan menggunakan enzim penisilinase sebagai peneguhan. Hasil negatif harus tidak membentuk zona hambatan. Konsentrasi antibiotika yang berada dalam sampel dapat ditentukan secara semi kuantitatif. Apabila zona hambatan di sekitar kertas indikator semakin luas maka semakin tinggi konsentrasi residu antibiotika dalam sampel.

\section{HASIL DAN PEMBAHASAN}

Hasil pengujian dari kandungan residu antibiotika golongan penisilin, makrolida, aminoglikosida, dan tetrasiklin pada paruparu sapi bali yang berasal dari beberapa pasar tradisional di lima kabupaten/kota Provinsi Bali sebanyak 30 sampel dengan masing masing enam sampel setiap kabupaten dapat dilihat pada Tabel 1.

Tabel 1. Hasil residu antibiotika pada paru-paru sapi bali di provinsi Bali

\begin{tabular}{lllllll}
\hline \multirow{2}{*}{ No } & \multirow{2}{*}{ Kabupaten } & \multirow{2}{*}{ Jumlah } & \multicolumn{4}{c}{ Jenis Antibiotika } \\
\cline { 4 - 7 } & & Penisilin & Tetrasiklin & Aminoglikosida & Makrolida \\
\hline 1 & Gianyar & 6 & Negatif & Negatif & Negatif & Negatif \\
2 & Tabanan & 6 & Negatif & Negatif & Negatif & Negatif \\
3 & Buleleng & 6 & Negatif & Negatif & Negatif & Negatif \\
4 & Jembrana & 6 & Negatif & Negatif & Negatif & Negatif \\
5 & Karangasem & 6 & Negatif & Negatif & Negatif & Negatif \\
\hline
\end{tabular}

Berdasarkan pengamatan yang dilakukan pada 5 lokasi pengambilan sampel menunjukkan bahwa $100 \%$ paruparu negatif atau tidak mengandung residu antibiotika. Hal ini dibuktikan dengan tidak terbentuknya zona hambatan pertumbuhan bakteri pada media agar masing masing antibiotika. Tidak ditemukannya residu antibiotika dari golongan penisilin, aminoglikosida, tetrasiklin, dan makrolida pada seluruh sampel yang diuji dapat disebabkan oleh karena pemahaman peternak dalam penggunaan antibiotika sudah memperhatikan masa henti obat dan dosis yang tepat (Donkor et al., 2011). Hasil tersebut juga dapat terjadi karena penggunaan antibiotika sebagai imbuhan pakan tidak digunakan pada peternakan sapi bali di provinsi Bali. Tidak seperti peternakan ayam yang masih menggunakan antibiotika sebagai growth promotor yang ditambahkan pada imbuhan pakan karena jika dilakukan terus menerus dapat memperbesar hasil residu antibiotika.

Hasil tersebut juga dapat terjadi karena penggunaan antibiotika sebagai imbuhan 
pakan tidak digunakan pada peternakan sapi bali di Provinsi Bali. Menurut Masrianto (2013), gambaran ini menunjukkan beragamnya penggunaan antibiotik di setiap daerah. Dilapangan, penggunaan antibiotik lebih sering digunakan pada peternakan-peternakan ayam, dan sapi perah. Dalam peternakan ayam digunakannya antibiotik ditujukan untuk preventif infeksi bakteri dan sekaligus sebagai perangsang pertambahan berat badan. Sedangkan di peternakan sapi perah antibiotik sering digunakan untuk anti mastitisJika pakan yang dicampur antibiotika secara terus menerus, maka residu antibiotika tersebut akan terakumulasi di dalam jaringan dengan konsentrasi yang bervariasi antara organ tubuh (Bahri et al., 2005) dan akan memperbesar kemungkinan terjadinya residu dan juga karena farmakokinetika obat pada fase farmakokinetika yaitu, arbsorpsi, transpor, biotransformasi, distribusi dan ekskresi.

Residu dari semua jenis obat hewan paling tinggi terdapat dihati dan ginjal dibandingkan pada jaringan otot. Hal ini dikarenakan organ hati berfungsi sebagai tempat akumulasi. Kadar residu antibiotik yang terakumulasi di hati dan semua obat akan di transfer ke hati untuk mengalami metabolisme. Hati mempunyai banyak tempat pengikatan senyawa- senyawa yang tidak bisa di detoksikasi atau tidak bisa di ekskresikan. Keadaan tersebut menyebabkan kadar residu obat termasuk antibiotik dalam hati juga menjadi lebih tinggi dibandingkan dengan kadar residu pada jaringan lain (Doul's, 1996)

Penelitian residu antibiotika dalam produk pangan asal hewan di Bali belum begitu banyak dilakukan, namun beberapa provinsi di Indonesia sudah banyak melakukan penelitian mengenai ini. Menurut Balai Pengujian Mutu Produk Peternakan (BPMPP) pada tahun 2009 dan 2010 yaitu ditemukan residu makrolida pada sampel daging sapi. Data yang diperoleh dari hasil uji BPMPP pada tahun 2009 dan 2010, ditemukan keberadaan residu antibiotik golongan makrolida pada sampel daging sapi sebanyak 4 sampel atau $7.27 \%$ (4/55) dan tidak ditemukan keberadaan residu antibiotik golongan apapun pada sampel daging ayam. Perbedaan dari hasil tersebut dapat dipengaruhi dari penggunaan dosis antibiotika yang tidak tepat dan tidak memperhatikan waktu henti obat.

Secara umum dampak negatif residu antibiotika pada produk hewan adalah dampak kesehatan (bahaya toksikologik, mikrobiologik dan imunopatologi) dan dampak ekonomi. Bahaya toksikologik diantaranya adalah mutagenik (terjadinya perubahan genetik), teratogenik (terjadinya cacat lahir), karsinogenik (pemicu kanker), bahaya mikrobiologis (resistensi pengobatan antibiotika dan gangguan pertumbuhan flora normal usus) dan bahaya imunopatologi (reaksi alergis). Residu antibiotika juga berdampak negatif bagi ekonomi karena dapat mengakibatkan penolakan produk terutama bila produk tersebut di ekspor ke negara yang konsisten dan serius dalam menerapkan sistem keamanan pangan (Dewi et al., 1997)

Menurut Martel et al. (2006), pencegahan cemaran antibiotika juga dapat dilakukan melalui penggunaan obat hewan yang harus sesuai dengan ketentuan yang berlaku dengan memperhatikan antara lain waktu henti dan kesesuaian dosis. Selain itu, penyimpanan obat hewan juga harus mengikuti petunjuk yang ada. Dengan memperhatikan waktu henti obat, pada saat memotong membuat keberadaan residu antibiotika dalam paru-paru dapat dihindari. atau telah berada dibawah batas maksimum residu (BMR) sehingga produk ternak aman dikonsumsi. Menurut Komisi Obat Hewan Departemen Pertanian, pemerintah memperbolehkan penggunaan antibiotika pada ternak dengan ketentuan, antibiotika yang digunakan pada manusia tidak boleh digunakan pada ternak, antibiotika yang digunakan harus aman bagi manusia, hewan, lingkungan dan memiliki efikasi yang bagus dan bermutu 
baik, khususnya untuk mencegah resisitensi bakteri pada manusia.

\section{SIMPULAN DAN SARAN}

\section{Simpulan}

Berdasarkan hasil dari penelitian dapat disimpulkan bahwa dari 30 sampel paruparu yang diperoleh dari beberapa pasar tradisional di Provinsi Bali tidak ditemukan adanya residu antibiotika dari golongan penisilin, makrolida, tetrasiklin, dan aminoglikosida.

\section{Saran}

Tetap perlu dilakukan pemantauan (monitoring) residu antibiotika produk pangan asal hewan baik organ dalam maupun daging sapi secara teratur agar produk pangan asal hewan yang beredar di pasar-pasar wilayah Bali semakin aman untuk dikonsumsi

\section{UCAPAN TERIMAKASIH}

Penulis mengucapkan terimakasih kepada Dekan Fakultas Kedokteran Hewan Universitas Udayana yang telah memfasilitasi pelaksanaan penelitian ini.

\section{DAFTAR PUSTAKA}

Bahri S, Masbulan E, Kusumaningsih A. 2005. Proses praproduksi sebagai faktor penting dalam menghasilkan produk ternak yang aman untuk manusia. $J$. Litbang. Pertanian, 24(1): 27-35.

Besung INK, Watiniasih NL, Mahardika GNK, Agustina KK, Suwiti NK. 2019. Mineral levels of bali cattle (Bos javanicus) from four different type of land in different rearing areas. Biodiversitas, 20(10): 2931-2936.

Chattopadhyay MK. 2014. Use of antibiotics as feed additives: a burning question. Front. Microbiol., 5(334): 13.

Dewi AAS, Agustini NLP, Dharma DMN. 1997. Survei residu obat perparat sulfa pada daging dan telur ayam di Bali. Buletin Vet., 10(51): 9-14.

Donkor ES, Newman MJ, Tay SCK, Dayie NTKD, Bannerman E, Olu-Taiwo M. 2011. Investigation into the risk of exposure to antibiotic residues contaminating meat and egg in Ghana. Food Cont., 22(6): 869-873.

Doul's C. 1996. Toxycology The Basic Science of Poisons Curtis D. Klaassen. $5^{\text {th }}$ Ed. Health Profesion Division. Mc. Graw- Hill. New York

Katzung BG. 2007. Basic and Clinical Pharmacology. $10^{\text {th }}$ Ed. United States: Lange Medical Publications.

Kussoy VFM, Kundre R, Wowiling F. 2019. Kebiasaan makan makanan tinggi purin dengan kadar asam urat di puskesmas. J. Keperawatan, 7(2): 1-7.

Maron, DF, Smith, TJ, Nachman, KE. 2013. Restrictions on antimicrobial use in food animal production: an international regulatory and economic survey. Glob. Health, 9(48): 1-11.

Martel AC, Zeggane S, Drajnudel P, Faucon JP, Aubert M. 2006. Tetracycline residues in honey after hive treatment. Food Additives Cont., 23(3): 265-273.

Masrianto, Fakhrurrazi, Azhari. 2013. Uji residu antibiotik pada daging sapi yang dipasarkan di pasar tradisional Kota Banda Aceh. J. Med. Vet. 7(1): 13-18.

Murtidjo BA. 2007. Pengendalian dan Hama Penyakit Ayam. Kanisius: Yogyakarta. Pp. 24-26.

Nugroho RH, Yulfitria HB. Dannoviarti S. 2002. Cemaran residu antibiotika dalam bahan pangan asal hewan di wilayah kerja BPPV Regional II Bukittinggi. Periode 1997-2002. Bulletin Inform. Kes. Hewan. 4(64): 1-4.

Phillips I, Casewell M, Cox T, Groot B, Friis C, Jones R, Nightingale C, Preston R, Waddell J. 2004. Does the use of antibiotics in food animals pose a risk to human health? J. Antimicrob. Chemotherapy, 53: 28-52. 